\title{
A ausência de um lugar enunciativo para as mulheres em o Conto da Aia: uma análise benvenistiana
}

\section{The absence of an enunciative place for women in The Handmaid's Tale: a benvenistian analysis}

\author{
Louise Ariane da Campo* \\ Carolina Alves Peres** \\ Suelen Aires Boettge $\mathrm{e}^{* * *}$
}

RESUMO: $O$ presente artigo tem o intuito de apresentar uma análise enunciativa da obra $O$ Conto da Aia de Margaret Atwood. Para isso, utilizou-se como aporte teórico-metodológico a teoria enunciativa de Émile Benveniste e, também, as reflexões acerca do sistema trinitário propostas por Dufour. O principal objetivo do trabalho é abordar a questão da falta de um lugar enunciativo para as mulheres na narrativa da obra. Para a realização da análise, levou-se em consideração as reflexões de Dufour sobre a tríade pronominal benvenistiana, principalmente no que diz respeito à noção de não-pessoa, a fim de demonstrar a falta de um lugar enunciativo para as mulheres e como elas são objetificadas de várias formas na narrativa.

PALAVRAS-CHAVE: Teoria enunciativa; não-pessoa; O Conto da Aia.

ABSTRACT: This article aims to present an enunciative analysis of Margaret Atwood's book The Handmaid's Tale. For that, it was used as theoretical-methodological support the enunciative theory of Émile Benveniste and also the reflections about the Trinitarian system proposed by Dufour. The main objective of the article is to address the issue of the lack of a place for women to enunciate in the narrative of the book. For carrying out the analysis, Dufour's reflections on the benvenistian pronominal triad were taken into account, mainly with regard to the notion of non-person, in order to demonstrate the lack of a place for women to enunciate and how they are objectified in various ways in the narrative.

KEYWORDS: Enunciative theory; non-person; The Handmaid's Tale.

* Mestranda em Letras na Universidade Federal de Pelotas, Jornalista pela Universidade Federal do Pampa, bolsista de produtividade do CNPq, dacampolouise12@gmail.com, ORCID oooo0002-0097-6367.

** Mestranda em Letras pela Universidade Federal de Pelotas, Designer Digital pela Universidade Federal de Pelotas, carolinaaperes@gmail.com, ORCID oooo-0001-5941-1654.

*** Mestranda em Letras pela Universidade Federal de Pelotas, especialista em Alfabetização e Letramento pela Uninter, suelenaires.revisora@gmail.com, ORCID oooo-0002-8124-7499. 
Como descrever o conjunto "eu", "tu", "ele", que partilhamos sem jamais nos darmos ao trabalho de falar disso e que transmitimos sem mesmo prestar atenção?4

\section{Introdução}

Este trabalho está inscrito na linguística enunciativa de Benveniste e apresenta um diálogo entre linguística e literatura, buscando reflexões sobre as possíveis formas de o sujeito se constituir na enunciação através de uma descrição do dispositivo trinitário eu-tu-ele, focando, principalmente, na não-pessoa, a fim de entender a falta de um lugar enunciativo para as mulheres na obra O Conto da Aia. Para realização da análise, leva-se em conta a proposta de Benveniste (1989) de que a língua é concebida como constituinte daquilo que mantém juntos os indivíduos, pois somente ela torna possível a sociedade. Também, considera-se a reflexão de Dufour (2000, p.19) de que "é no e pelo trinitário que os homens se formam como sujeitos falantes e formam sociedades"; o autor, inclusive, aponta o percurso para a análise quando observa que o sistema dos pronomes pessoais $e u$, tu e ele pode funcionar como "um dispositivo no interior da língua, que inscreve sempre em seus lugares o alocutário" (DUFOUR, 2000, p. 69), de modo que a loucura unária do eu se disciplina e entra no discurso ao dirigir-se a um $t u$, que lhe dá a garantia de sua própria existência.

A obra, publicada em 1985, é um romance distópico escrito pela autora Margaret Atwood; a história é uma ficção futurista que acontece em um Estado teocrático e totalitário chamado Gilead, onde apenas homens governam. Nesse contexto, as mulheres são propriedades do governo e não possuem direitos sobre seus corpos e suas vozes. O presente artigo propõe, então, através da tríade pronominal benvenistiana e das reflexões trazidas por Dufour em Os mistérios da trindade, abrir uma discussão sobre a falta de um lugar enunciativo para as

\footnotetext{
4 DUFOUR, 2000, p. 70.
} 
mulheres na narrativa de $O$ Conto da Aia e sobre a objetificação das mesmas nessa nova configuração social.

Sob a perspectiva da Teoria da Enunciação de Benveniste, entende-se que "a enunciação é este colocar em funcionamento a língua por um ato individual de utilização" (1989, p. 82), assim, a enunciação é vista como um processo de apropriação da língua, em que é necessário que o locutor se coloque em posição de eu e enuncie para um tu. O autor, portanto, explora as relações da língua como linguagem assumida e apropriada por um sujeito.

Benveniste (1989), ainda, define que o locutor da enunciação apropria-se do aparelho formal da língua e enuncia ao outro sua posição de locutor, e este ato individual de apropriação da língua instaura aquele que fala em sua fala. Segundo Dufour (2000), a díade eu-tu é a que mais se manifesta em termos fenomenológicos, pois basta que se abra a boca e já se está interpelando o alocutário em $t u$, e este, quando acaba de falar, dirá eu, por sua vez designando o outro como tu. Dessa forma, Dufour observa que eu e tu são inversíveis, afinal a qualidade específica do eu é imediatamente transferida àquele que era denominado como tu. Mas e aquele que não fala, a quem ninguém se dirige? $\mathrm{O}$ ele/ela 5 presente na enunciação é definido por Benveniste como não-pessoa, a quem as pessoas eu e tu se opõem. Para Dufour (2000) o ele/ela é definido como ninguém, pois re-presenta o que está ausente.

Dufour (2000) cita, outrossim, que a tríade pronominal eu-tu/ele pode ser vista em uma relação presente-copresente/ausente que, de um modo metafórico, poderia ser substituída pela relação entre vida/morte, sendo eu-tu, a vida, e ele, a morte. De acordo com o autor, essa metáfora "é necessária ao homem para tornar-se sujeito falante, [pois] se a morte não estivesse representada no sistema simbólico, o homem não poderia nem falar, nem estar presente” (DUFOUR, 2000, p. 98).

Em O Conto da Aia, às mulheres não é dado o direito de assumir a posição de pessoa na enunciação eu/tu: elas são colocadas na posição de não-pessoa

\footnotetext{
5 Ao escrever sobre a noção de não-pessoa, Benveniste usa apenas o pronome ele, no entanto optou-se, também, por utilizar neste artigo o pronome no feminino. Acredita-se ser correta essa escolha, pois o masculino não é tomado como padrão da linguagem.
} 


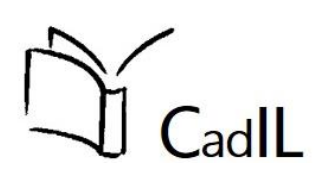

ele/ela. Tendo em vista as considerações de Dufour (2000), essas mulheres teriam perdido a vida, o ato de poderem se colocar como eu-tu em seus discursos e estariam fadadas à morte, à posição ele/ela. Para Benveniste (1976), o indivíduo apenas se constitui como sujeito na e pela linguagem, ocupando a posição de $e u$ e tu na enunciação. Uma vez que as Aias não se reconhecem em posição de pessoa dentro do espaço da enunciação, de que forma se constituem como sujeito? Assim, procura-se, através desta análise, contestar o lugar que essas mulheres ocupam dentro do novo modelo de estado em Gilead, problematizando a falta do espaço enunciativo imposto a elas.

\section{A noção de pessoa e de não-pessoa na teoria de Benveniste}

Benveniste é notadamente reconhecido como o autor que promove a discussão acerca da noção de pessoa e não-pessoa na linguística enunciativa. Para o linguista, o fundamento da subjetividade do indivíduo se dá através de uma relação com o interlocutor, ou seja, o tu. Nesse sentido, as formas linguísticas $e u / t u$ são consideradas pelo autor como pessoa. O eu e o tu possuem "traços em comum" que permitem que ambos possam estar nessa mesma categoria (FLORES, 2013, p. 90).

Benveniste (1976) vai opor os signos que são referenciados na instância do discurso àqueles que têm referência objetiva. Os signos vazios eu e tu são considerados pelo autor os responsáveis pela passagem da língua para discurso e, também, pela subjetividade na linguagem.

Já os signos plenos são considerados com o mesmo estatuto do ele/ela, a não-pessoa, ou seja, remetem a uma situação objetiva e não a eles mesmos como os signos vazios, que “[d]esprovidos de referência material, não podem ser mal empregados; não afirmando nada, não são submetidos à condição de verdade e escapam a toda negação." (BENVENISTE, 1976, p. 280).

Dufour (2000), apoiado em Benveniste, afirma que os dois termos eu/tu não estão no mesmo plano: 
[...] "eu" e "tu" são desiguais: "eu" é sempre transcendente com relação a "tu", "tu" é necessariamente designado por "eu" e não pode ser pensado fora de uma situação exposta a partir do "eu", escreve Benveniste. [...]. A dominância do "eu" constitui um dos caracteres fundamentais de nosso espaço simbólico. (DUFOUR, 2000, p. 83).

Segundo a teoria de Benveniste, os termos $\mathrm{eu} / \mathrm{tu}$ se referem à forma linguística de pessoa no discurso. Toda vez que o locutor diz eu, ele se apresenta como sujeito e ao mesmo tempo propõe o tu, que, em seguida, será o eu do discurso, isto é, “[...] a forma eu só têm existência linguística no ato de palavras que a profere" (BENVENISTE, 1976, p. 279, grifo do autor). Fora da instância de discurso, a enunciação não verifica o referente, pois “a referência é parte integrante da enunciação" (BENVENISTE, 1989, p. 84).

Existe nessa díade $e u / t u$ uma reversibilidade da posição que cada um ocupa no momento em que o discurso é instaurado, ou seja, é eu aquele que toma a palavra no discurso e, necessariamente, estabelece um tu a quem o discurso é dirigido. Conforme Dufour (2000, p.73), “o que se troca nessa inversão é, antes de tudo, a qualidade específica do 'eu': ela é imediatamente transferida àquele que era denominado 'tu'.”

O que comprova essa possibilidade de reversão é que a linguagem está de tal forma organizada que permite a cada locutor apropriar-se da língua toda designando-se como eu (BENVENISTE, 1976). No entanto, não existe igualdade nem simetria entre eles, porque

[...] ego tem sempre uma posição de transcendência quanto a tu; apesar disso, nenhum dos dois termos se concebe sem o outro; são complementares, mas segundo uma posição "interior/exterior", e ao mesmo tempo são reversíveis. (BENVENISTE, 1976, p. 286-287, grifos do autor).

Para provar que as duas primeiras pessoas não estão no mesmo nível que a terceira, Benveniste (1976) faz um inventário da terceira pessoa em diferentes línguas, verificando seu uso. Alguns exemplos dessa comprovação de Benveniste são: 
[n]o semítico, a terceira sing. do perfeito não tem desinência. No turco, de maneira geral, a terceira do sing. tem a marca zero, em face da primeira sing. $-\mathrm{m}$ e da segunda sing. $-\mathrm{n} ; . .$. No ugro-fínico, a terceira do sing. representa o tema nu. (BENVENISTE, 1976, p. 251).

Entende-se, portanto, que, nessas línguas, tratar num mesmo plano a tríade eu/tu e ele/ela é um erro, pois a considerada terceira pessoa “[...] é sempre tratada diferentemente e não como uma verdadeira pessoa verbal e que a classificação uniforme em três pessoas paralelas não convém ao verbo dessas línguas. " (BENVENISTE, 1976, p. 252).

Na teoria enunciativa que Benveniste propõe, o ele/ela integra a noção de não-pessoa, “[...] a 'terceira pessoa' é a forma do paradigma verbal (ou pronominal) que não remete a nenhuma pessoa, porque se refere a um objeto colocado fora da alocução.” (BENVENISTE, 1976, p. 292). Em outras palavras, "[a] forma dita de terceira pessoa comporta realmente uma indicação de enunciado sobre alguém ou alguma coisa, mas não referida a uma 'pessoa' específica” (BENVENISTE, 1976, p. 250).

Sendo o terceiro pronome considerado o ausente na instância de discurso, é ele mesmo responsável pela presença dos outros, o eu e o tu (DUFOUR, 2000, p. 91). Consequentemente, só se pode falar em pessoa quando se trata de eu ou tu, pois, como aponta Dufour (2000), o ele/ela é o ausente, se fala dele/dela.

[...] "Ele" é, pois, forma não-pessoal num segundo sentido: não somente ele não vem indexar, necessariamente, uma pessoa, mas, além disso, quando é o caso, pode não corresponder exatamente à pessoa, pode significar a promoção ou aniquilamento de uma pessoa; pode, em suma, indicar mais ou menos que uma pessoa. (DUFOUR, 2000, p. 109, grifos do autor).

O ele/ela não está autorizado a participar do diálogo num processo de enunciação, justamente por se tratar do ausente no discurso e, com isso, é um outro quem fala em seu lugar. Ao não ocupar a posição enunciativa, entende-se que alguém não está em posição de fala, ou seja, lhe é cerceada a possibilidade de ter voz.

Flores (2013, p. 91) destaca que a diferença entre a categoria de pessoa $e u$ e tu e de não-pessoa ele/ela é evidenciada através de três características: 1) Eu e 
tu são únicos, já o ele pode ser um número infinito de sujeitos ou nenhum. 2) Eu e tu são inversíveis entre si, porém o ele/ela não pode ser invertido com os anteriores. 3) A terceira pessoa é a única em que uma coisa é predicada verbalmente.

Benveniste não desenvolve um modelo de metodologia para análise, como observa Cavalheiro (2006). No entanto, encontra-se suporte teóricometodológico na leitura que esta autora fez da tríade pronominal benvenistiana para pensar a relação de alteridade na obra $A$ Metamorfose de Franz Kafka e que derivou indicações de procedimentos de análise compatíveis com o objetivo que se está propondo neste trabalho, o de se analisar a falta de um espaço enunciativo para as mulheres em $O$ Conto da Aia.

\footnotetext{
O intercâmbio e as relações de alteridade são definidos, em termos linguísticos, por um conjunto de três pessoas: o "eu", o "tu" e o "ele". Assim, a subjetividade, em Benveniste, não pode ser conhecida em si mesma, mas em relação com o outro. É essa relação de intersubjetividade que será contemplada na análise da obra em questão. (CAVALHEIRO, 2006, p. 81).
}

A fim de encontrar indícios que comprovam a presença da personagem principal na categoria nomeada pela teoria enunciativa como não-pessoa, observa-se as relações que são estabelecidas com o outro e sua trajetória através do dispositivo dos pronomes na instância de discurso.

\section{3 apagamento do eu em O Conto da Aia}

Para Benveniste (1989, p. 98), “[...] a língua interpreta a sociedade. A sociedade torna-se significante na e pela língua [...]”. Em O Conto da Aia, a personagem principal é tratada na sociedade em que vive como Offred, embora já tivesse um nome, June. Nessa nova configuração sociopolítica, a mulher perde o direito de usar seu próprio nome e é identificada através do nome de seu comandante. Offred é a união de $O f$ mais o nome de seu comandante Fred - na tradução do inglês se tem de Fred. Nesse sentido, o nome próprio (June, por 
exemplo) apenas designa, ele não possui um significado, no entanto, quando se troca o nome da aia, atribuiu-se um significado a esse nome, ou seja, demonstrase que a mulher tornou-se propriedade de um homem. Assim, a língua é utilizada para construir essa nova sociedade, já que essa organização se estabelece a partir de uma nova forma de se relacionar com a língua, o que se percebe na criação de novos vocábulos, nas novas combinações, nas novas interdições etc.

Quando esses novos líderes assumem o comando do Estado, através de um golpe, as mulheres são perseguidas, retiradas de suas casas e separadas de suas famílias. Antes de Gilead, June vivia com o marido e a filha, porém, após o golpe, foi separada de ambos e nunca mais os viu. Cada mulher recebe um destino diferente, a partir da vida que levava. As mulheres LGBT ou participantes de movimentos de resistência vão para os campos de trabalho escravo, para a casa de prostituição ou são mortas. As mulheres inférteis são destinadas a trabalhar como empregadas domésticas nas casas dos comandantes e são chamadas de Marthas. Já as mulheres férteis e/ou que já tiveram filhos são enviadas para os Centros Vermelhos, onde são treinadas para se tornarem aias, ou seja, barrigas de aluguel para as famílias que estão no poder. É através desse novo vocabulário que as mulheres são classificadas e separadas, segundo os papéis que desempenham, segundo Benveniste (1989), a língua é capaz de acolher e nomear todas as novidades da vida social.

As vidas dessas mulheres são apagadas de diversas formas: elas perdem o direito de usar o nome de registro, não podem mais utilizar as mesmas roupas (as aias utilizam um vestido vermelho, semelhante a uma burca, e um chapéu branco para cobrir o rosto), não detêm o poder de expressar opiniões, ler ou de sequer relembrar suas vidas antes do golpe. Seus corpos são agora propriedades do Estado.

O viver se torna uma questão de sobrevivência, pois depois de perder tudo aquilo que era familiar a si, a protagonista entende que as restrições precisam se estender ao nível de pensamento também, visto que ela não está livre de sucumbir à loucura: “Tento não pensar demais. Como outras coisas agora, os pensamentos 
têm que ser racionados. Há muita coisa em que não é produtivo pensar. Pensar pode prejudicar suas chances, e eu pretendo durar." (ATWOOD, 2017, p. 16).

Boa parte da narrativa se dá através de conversas de June com ela mesma em sua consciência. Na falta de alguém para dialogar, June acaba criando extensas conversas que são desenvolvidas em sua própria mente; ela trata a si mesma como o outro. Dessa forma, a personagem acaba se desdobrando entre eu e tu em vários momentos da narrativa, como exemplifica o trecho a seguir: "Fingirei que você pode me ouvir. Mas não adianta, porque sei que não pode." (ATWOOD, 2017, p. 52).

A reversibilidade entre eu/tu tomada enquanto troca entre papéis sociais é perdida na nova vida de June, pois ela não possui relações reais com outros indivíduos. Contudo, encontra-se essa reversibilidade na relação da personagem com ela mesma, o que, de certa forma, apresenta-se como uma espécie de refúgio para June. Vivendo como Offred, é como se a todo momento ela estivesse no corpo de uma outra pessoa, dado que não reconhece a si própria como Offred. Nesse sentido, Offred seria a não-pessoa da própria June. São tão raros os momentos em que a personagem tem diálogos reais que, quando acontecem, sua excitação não passa despercebida.

\footnotetext{
Nós andamos, de cabeça baixa como de hábito. Estou tão entusiasmada que mal consigo respirar, mas mantenho um passo regular. Agora mais do que nunca tenho que evitar atrair atenção para mim mesma.

- Pensei que você fosse uma verdadeira crente - diz Ofglen.

- E eu pensei que você fosse - digo.

- Você era sempre tão insuportavelmente devota.

- Você também - respondo. Tenho vontade de rir, gritar, abraçá-la. (ATWOOD, 2017, p. 202).
}

Isso é significativo, porque ser reconhecido como tu permite ao indivíduo a condição de ser um eu. Para Dufour (2000, p. 55), para ser um sujeito, é necessário a todo o momento estar mudando de posição, pois é assim que os interlocutores "se afirmam mutuamente como presentes". Essa falta de contato que a personagem vive, age como uma violência psíquica, algo que ela demonstra sentir no trecho: "Como eu costumava desprezar esse tipo de conversa. Agora 
anseio por elas. Pelo menos eram conversas. Uma troca, por menor que fosse.” (ATWOOD, 2017, p. 19).

Segundo Benveniste (1976), a consciência de si mesmo só acontece através de contraste. Para empregar o eu, é preciso se dirigir a alguém, ou seja, um tu.

\begin{abstract}
Essa condição de diálogo é que é constitutiva da pessoa, pois implica em reciprocidade - que eu me torne tu na alocução daquele que por sua vez se designa por eu. [...] A linguagem só é possível porque cada locutor se apresenta como sujeito, remetendo a ele mesmo como eu no seu discurso. Por isso, eu propõe outra pessoa, aquela que, sendo embora exterior a "mim", torna-se o meu eco - ao qual digo tu e que me diz tu. (BENVENISTE, 1976, p. 286, grifos do autor).
\end{abstract}

Com o não pertencimento à categoria de pessoa, as aias são retratadas como mulheres que buscam dar novamente um sentido para suas existências, já que perderam tudo aquilo que conheciam devido ao apagamento de suas vidas, direitos e vontades. Quando a aia Ofglen, parceira de compras da June, diz "Pensei que você fosse uma verdadeira crente" (ATWOOD, 2017, p. 202), June descobre que a outra, assim como ela mesma, não perdeu as esperanças e não é devota ao Estado. Com isso, tem um pico de excitação. O que é explicado não apenas pela questão de estar desenvolvendo um diálogo em que é reconhecida como tu, mas também porque:

\footnotetext{
Este sujeito que perdeu o amparo das certezas constituídas pelas formações simbólicas das sociedades tradicionais, condenado a viver no isolamento de seu próprio eu, tem nos seus semelhantes, se não um amparo, um espelho. Se não uma garantia de verdade, um interlocutor para a incerteza. (KEHL, 2001, p. 8).
}

Para Benveniste (1989, p. 101), “cada um se determina como sujeito com respeito ao outro ou a outros". Nesta passagem, quando Ofglen fala "Pensei que você fosse uma verdadeira crente" e June responde "E eu pensei que você fosse", ambas se determinam como sujeito com respeito uma à outra e, dessa forma, entendem que não estão só. Para Ofglen, é mais uma mulher que irá se juntar ao seu grupo de resistência e, para June, é um amparo encontrado naquelas mulheres que são semelhantes a si, o entendimento de que ainda há possibilidade de escapar da nova condição de vida à qual foi imposta. A própria personagem 
June afirma esse reconhecimento em uma passagem do livro: "Ela é como um reflexo de mim mesma, em um espelho do qual estou me afastando" (ATWOOD, 2017, p. 57).

Nessa conversa, Ofglen conta que existe um nós, ou seja, um grupo de pessoas que é contra o Estado e que trabalha em conjunto. Para descobrir quem faz parte do grupo, é preciso utilizar a palavra "Mayday" em alguma conversa casual; se a pessoa a reconhecer, é porque faz parte do grupo, porém é preciso cautela ao usá-la para garantir segredo e segurança. Aqui, percebe-se, mais uma vez, como a língua estabelece a organização da sociedade, quando se pode, através de uma forma, buscar os iguais nesse regime ditatorial.

Por se acostumar com a posição de não-pessoa ela, a própria protagonista possui dificuldade de admitir seu pertencimento a algum lugar: "A porta do quarto - não de meu quarto, eu me recuso a dizer meu” (ATWOOD, 2017, p. 16, grifos da autora). O desaparecimento do eu implica a não aceitação de algo como seu. Na prática social, as relações são todas impessoais, por que deveria ela aceitar algo como pertencente a si mesma? "Estaria ele invadindo? Será que esteve em meu quarto? Eu o chamei de meu." (ATWOOD, 2017, p. 62, grifos da autora). A partir do momento em que se inclui como sujeito e reconquista sua subjetividade, June aceita considerar que pelo menos algo possa ser seu nessa nova configuração de sociedade, "meu quarto, então, que seja. Tem de haver algum espaço, afinal, que eu chame de meu, mesmo neste tempo" (ATWOOD, 2017, p. 63).

Em suas divagações, June assume eu por sua própria conta e se direciona a um tu, mesmo que em dado momento não reconheça sua existência de fato.

Mas se for uma história, mesmo em minha cabeça, devo estar contando-
a a alguém. Você não conta uma história apenas para si mesma. Sempre
existe alguma outra pessoa. Mesmo quando não há ninguém. (...) Eu
direi você, você, como uma velha canção de amor. Você pode ser mais
de uma pessoa. Você pode significar milhares. (ATWOOD, 2017, p. 52,
grifos da autora).

Conforme esclarece Benveniste (1976), a linguagem, por conter formas linguísticas que são apropriadas para sua expressão, é a possibilidade da 
subjetividade. De algum modo, ela "propõe formas 'vazias' das quais cada locutor em exercício de discurso se apropria e as quais refere à sua 'pessoa', definindo-se ao mesmo tempo a si mesmo como eu e a um parceiro como tu." (BENVENISTE, 1976, p. 289, grifos do autor).

Dentre todas as privações que a personagem sofre, o silêncio é uma das mais significativas, sendo raros os diálogos que June tem com outros personagens. Dentro da residência em que vive, ela é constantemente coisificada, não apenas pelos comandantes, mas por suas esposas e pelas Marthas. As esposas dos comandantes não gostam das aias, pois se sentem ameaçadas, já as Marthas acreditam que as aias não são dignas de respeito, porque "entregam" seus corpos para os comandantes. Em um momento da narrativa, as duas Marthas que trabalham na casa onde June vive discutem sobre um determinado banho.

- Quem vai cuidar do banho? - pergunta Rita, para Cora, não para mim.

- Tenho que amaciar e temperar esta ave.

- Cuido disso mais tarde - diz Cora -, depois de espanar a casa.

- Apenas não deixe de tratar de fazê-lo - diz Rita.

Elas estão falando de mim como se eu não pudesse ouvir. Para elas eu sou uma tarefa doméstica, uma dentre muitas. (ATWOOD, 2017, p. 61).

Apesar de estar presente no mesmo local que as Marthas, June é tratada como ela, sendo caracterizada como uma não-pessoa. Para Benveniste (1976, p. 254), esse uso da forma não-pessoal através da terceira pessoa pode se caracterizar como uma forma de ultraje, anulando o indivíduo como pessoa, sendo "um testemunho de menosprezo, para rebaixar aquele que não merece nem mesmo que alguém se dirija 'pessoalmente' a ele".

Dufour reforça ao citar Benveniste, “Ele (ou ela) pode servir de forma de alocução diante de alguém que está presente quando se quer subtraí-lo à esfera pessoal do 'tu' ('vós')" (BENVENISTE apud DUFOUR, 2000, p. 108, grifos do autor) e, ainda, ressalta que “[s]endo aquele que não está, 'ele' se refere, portanto, realmente à ausência. Mas isso não diz o essencial: a ausência denotada por 'ele' é uma ausência re-presentada no campo da presença” (DUFOUR, 2000, p. 106107, grifos do autor), ou seja, mesmo estando presente no aqui e agora, como no 
caso de June, ela é ausentificada no discurso, pois o uso da terceira pessoa faz referência à ausência. É o ele/ela que possibilita a cena da representação.

Não apenas June vive o anulamento constante, mas toda a categoria de aias. As esposas dos comandantes não possuem afeto por elas e as enxergam apenas como escravas. $\mathrm{O}$ menosprezo que sentem aparece frequentemente em seus diálogos. Em um momento da história, as esposas e as aias se reúnem em uma casa para o nascimento de uma criança (o nascimento é tido como um grande evento), algumas delas estão reunidas ao redor de uma mesa de comida. June e outra aia, chamada Janine, estão próximas ao local. Uma das esposas oferece um doce para Janine que, educadamente, aceita, e em sua presença as esposas falam como ela é educada: “(...) não é grosseira e rabugenta como algumas delas (...)" (ATWOOD, 2017, p. 140), porém, no momento em que Janine se retira, o tom da conversa muda e quem ouve é June, a personagem principal.

\footnotetext{
E depois que ela saiu: Umas putinhas, todas elas, mas apesar disso não se pode ser exigente demais. Você aceita o que eles oferecem, certo, meninas? Isso da Esposa do Comandante. Ah, mas você teve tanta sorte. Algumas delas, ora veja, não são nem sequer limpas. E não lhe darão um sorriso, ficam lastimando-se em seus quartos, não lavam o cabelo, elas fedem. (ATWOOD, 2017, p. 140).
}

Quando June está no mesmo ambiente que a esposa do comandante, ela percebe esse testemunho de menosprezo e anulamento na forma de atitude também, uma vez que, apesar de a esposa estar ciente de sua presença, não demonstra esforço algum para reconhecê-la. "Ela não vira a cabeça. Não reconhece minha presença de nenhuma maneira, embora saiba que estou ali. Sei muito bem que ela sabe, é como um cheiro seu saber; alguma coisa que azedou, como leite." (ATWOOD, 2017, p. 59).

Contudo, o menosprezo e o anulamento não existem apenas para com as aias, mas sim com todas as mulheres dessa sociedade. Em um sistema tão opressor e misógino como o de Gilead, nenhuma mulher, independente de classe, possui direitos. A opressão acontece de forma tão brutal que as próprias mulheres se colocam umas contra as outras, e o menosprezo é o principal sentimento de suas relações. June vê com desprezo as vezes em que a esposa do comandante fica 
doente, a empatia é inexistente: "Elas ficam doentes com frequência, essas Esposas de Comandante. Isso acrescenta interesse às suas vidas. Quanto a nós, as Aias e mesmo as Marthas, evitamos doenças.” (ATWOOD, 2017, p. 185).

Em relação às Marthas, June apresenta indiferença, como na passagem: “- Está bem - respondo. Não sorrio. Por que tentá-la com amizade?” (ATWOOD, 2017, p. 20), pois sabe que, mesmo se tentar, as Marthas continuarão anulando sua presença e não se permitirão confraternizar com ela.

Esse ódio existente entre elas surge através de uma espécie de lavagem cerebral que é utilizada antes e durante o golpe. Os comandantes são os principais responsáveis por isso, são eles que alimentam esse ódio às mulheres e as culpam por todas as desgraças que pairam no mundo. Em um casamento coletivo que acontece em Gilead, um comandante é responsável por discursar e “abençoar" o matrimônio. Em seu discurso, profere passagens da Bíblia, a fim de embasar seu discurso de ataque às mulheres:

Que a mulher aprenda em silêncio com toda a sujeição. Aqui ele lança um olhar para nós. - Toda - repete ele.

- Mas não tolerarei que uma mulher ensine, nem que usurpe a autoridade do homem, apenas que se mantenha em silêncio. Pois primeiro Deus criou Adão, depois Eva. (ATWOOD, 2017, p. 262).

O uso da Bíblia é o principal elemento para fundamentar os discursos e decisões tomadas nessa sociedade. A própria ideia de usar as mulheres férteis como barrigas de aluguel para as famílias do poder é retirada de uma passagem bíblica, ${ }^{6}$ e isso é consolidado através da repetição desses textos sagrados. Para finalizar seu discurso no casamento, o comandante diz: "Não obstante isso ela será salva pela concepção, se continuar na fé e caridade e santidade com sobriedade" (ATWOOD, 2017, p. 262), fala que é direcionada, principalmente, para as aias, a fim de mantê-las submissas.

\footnotetext{
${ }^{6}$ A passagem bíblica é a seguinte: "Vendo, pois, Raquel que não dava filhos a Jacob, teve Raquel inveja da sua irmã, e disse a Jacob: Dá-me filhos, ou senão eu morro. Então se acendeu a ira de Jacob contra Raquel e disse: Estou eu no lugar de Deus, que te impediu o fruto de teu ventre? E ela lhe disse: Eis aqui a minha serva, Bilha; Entra nela para que tenha filhos sobre os meus joelhos, e eu, assim, receba filhos por ela. - GÊNESIS, 30:1-3."
} 
Para a instituição dessa sociedade patriarcal, foram usados discursos de mulheres também. Um exemplo é Serena Joy, a esposa do comandante de June. Quando as modificações começaram a acontecer, ela discursava sobre a santidade do lar e sobre como as mulheres deveriam ficar em casa e exercer tarefas domésticas. June reconhece que o apagamento do eu e a perda desse lugar enunciativo, também, estende-se às esposas de comandantes, e comenta: "Ela não faz mais discursos. Tornou-se incapaz de falar. Fica em casa, mas isso não parece lhe fazer bem. Como deve estar furiosa, agora que suas palavras foram levadas a sério.” (ATWOOD, 2017, p. 58).

No Centro Vermelho, durante o treinamento para se tornarem aias, as mulheres são bombardeadas a todo o momento com informações relacionadas aos seus deveres e às consequências se não os cumprirem. Como uma forma educativa do que não fazer, elas precisam assistir a diversos vídeos que vão de imagens de manifestantes feministas até vídeos pornográficos. Quem apresenta esses materiais são as chamadas Tias, mulheres que são responsáveis pelo treinamento e que possuem certo poder na sociedade. O uso dos vídeos tem o intuito de mostrar como a sociedade anterior era doente e como agora elas vivem em um local saudável e correto. As mulheres que aparecem nas telas são chamadas de não mulheres. Um dos vídeos é de uma situação banal: uma mulher caminhando na rua.

Ela está vestindo o tipo de roupas que tia Lydia nos disse que eram típicas das Não mulheres naquela época, macacão de jeans com uma camisa xadrez verde e cor de malva por baixo e calçando tênis; o tipo de coisa que Moira outrora usava, o tipo de coisa que me lembro de ter usado, há muito tempo, eu mesma. (ATWOOD, 2017, p. 146).

No momento em que June se reconhece no vídeo, ela passa por um conflito: se aquela na imagem é uma Não mulher, não teria sido ela uma também? Essa dificuldade de reconhecimento de si mesma que June passa em vários momentos representa uma perda de sua própria identidade.

Posteriormente, ao se deparar com mulheres turistas em Gilead, os pensamentos de June sobre os tipos de vestimentas comuns da atualidade se modificam: 
[...] sei que ela [Ofglen] também não consegue tirar os olhos daquelas mulheres. Estamos fascinadas, mas ao mesmo tempo sentimos repulsa. Elas parecem despidas. Foi preciso tão pouco tempo para mudar nossas ideias a respeito de coisas como essa. (ATWOOD, 2017, p. 40).

A personagem percebe a mudança de pensamento à qual foi submetida, mas parece não compreender o que foi responsável por modificar sua percepção a respeito de coisas que antes eram banais.

Benveniste (1989, p. 96) explica que linguagem e sociedade implicam uma a outra e são realidades inconscientes, não sendo passíveis de mudanças. Aquilo que os indivíduos podem mudar e o que efetivamente mudam são "as instituições, às vezes a forma inteira de uma sociedade particular”. Os treinamentos nesse novo Estado conseguem de fato aplicar isso, modificando totalmente a cultura através das crenças, costumes e posições sociopolíticas, via linguagem.

Outro momento importante da narrativa é a relação que June acaba tendo com seu comandante ao se tornar sua amante. Para a personagem, um dos momentos mais surpreendentes é sua ida ao chamado Clube, mas que é conhecido como Casa de Jezabel7. Nesse local, diversas mulheres - garotas de programa profissionais ou mulheres que cometeram crimes - se prostituem para os comandantes. June vai à casa como acompanhante de seu comandante. June vê o local com surpresa, já que o sexo por mero prazer é proibido por uma lei criada pelos mesmos homens que estavam frequentando a Casa de Jezabel. Ao questionar o comandante sobre a existência do local, ele responde:

Natureza exige variedade para homens. É lógico, razoável, faz parte da estratégia de procriação. É o plano da Natureza. - Não digo nada, de modo que ele prossegue. - As mulheres sabem disso instintivamente. Por que elas compravam tantas roupas diferentes, nos velhos tempos? Para enganar os homens levando-os a pensar que eram várias mulheres diferentes. Uma nova a cada dia. (ATWOOD, 2017, p. 281).

O próprio discurso do comandante é carregado de menosprezo e o uso da terceira pessoa enfatiza ainda mais esse sentimento ao tratá-las como não-pessoa. Seu discurso demonstra que as mulheres são objetos, dessa forma, seus desejos,

\footnotetext{
7 Na Bíblia Jezabel é dita como uma mulher que seduzia os servos a praticarem prostituição.
} 
suas opiniões, tampouco suas carreiras importam. Elas são apenas propriedades destinadas ao uso dos homens, isso é exposto quando ele diz:

Bem, temos uma coleção e tanto. Aquela ali, a de verde, é uma socióloga. Ou era. Aquela era uma advogada, aquela outra era administradora de empresa, tinha um cargo executivo em algum tipo de grande rede de fast-food ou talvez fosse de hotéis. Disseram-me que se pode ter uma conversa muito boa com ela se só o que você quiser for conversar. (ATWOOD, 2017, p. 282).

Nessa nova configuração cultural em que a personagem vive, existe uma definição do que uma mulher deve fazer, vestir, falar e de como ela deve ser. Isso se consolida através da linguagem, quando, repetidamente, os comandantes e as Tias reproduzem esses discursos. Conforme Benveniste apud Neumann (2018), o indivíduo assimila, perpetua ou transforma a cultura através da língua. Nesse contexto, a linguagem "reproduz o mundo, mas submetendo-o à sua própria organização” (BENVENISTE apud NEUMANN, 2018, p. 438).

A linguagem é uma questão política muito significativa em Gilead, é ela que define as posições sociais de cada ser e que divide as mulheres em setores, conforme suas funções: aias, esposas, Tias, não mulheres, traidoras de gênero. Nessa conjuntura, algumas palavras se tornam proibidas (como infértil, por exemplo) e outras são ressignificadas, como a palavra serviço, que, no passado, podia ser relacionada a mulheres, mas nessa nova circunstância perde o sentido: "É estranho, agora, pensar em ter um trabalho, um serviço. É uma palavra engraçada. Isso é serviço para homem.” (ATWOOD, 2017, p. 207). Benveniste (1989, p. 100) afirma que o vocabulário é muito importante para compreender as "formas e as fases da organização social” e os regimes políticos.

O capítulo final do livro, intitulado Nota histórica, passa-se 200 anos depois da trama que é contada por June. Após a queda de Gilead, os escritos de June são estudados por pesquisadores e historiadores a fim de entender essa sociedade. Nesse momento, o leitor descobre que estava a todo o tempo lendo uma espécie de diário da personagem, onde a mesma desabafava sobre sua condição e relatava seus dias em Gilead. 
Em seus últimos relatos, June escreve que a esposa do comandante a procurou preocupada com a demora que ela estava tendo para engravidar e sugerindo que ela procurasse outro homem, pois havia uma possibilidade de o comandante ser estéril. June encara essa proposta com desconfiança e medo, mas a esposa do comandante afirma que acertará tudo e que ninguém ficará sabendo. Dessa forma, a esposa escolhe um funcionário da casa, Nick, para desempenhar a tarefa de engravidar June. No entanto, eles acabam tendo um relacionamento, e é através desse relacionamento que June se ressignifica como ser humano. “Conto-lhe coisas que não deveria." (ATWOOD, 2017, p. 318). "Digo-lhe meu verdadeiro nome, e sinto que portanto sou conhecida." (ATWOOD, 2017, p. 318). Ter alguém para chamar de tu é a ressignificação de sua própria subjetividade.

Porém, quando a esposa do comandante descobre que June também havia se relacionado com seu marido, sua vida volta a se tornar um tormento. June se desespera com a possibilidade de nunca mais rever sua filha e aceita sua condição de mulher submissa:

\footnotetext{
Não quero dor. Não quero ser uma dançarina, com os pés no ar, minha cabeça um retângulo sem rosto de pano branco. Não quero ser uma boneca dependurada no Muro, não quero ser um anjo sem asas. Quero continuar vivendo, de qualquer forma que seja. Renuncio a meu corpo voluntariamente, para submetê-lo ao uso de outros. Eles podem fazer o que quiserem comigo. Sou abjeta. (ATWOOD, 2017, p. 337-338).
}

June já sabe que está grávida de Nick e que as esperanças para ela são poucas. Seu último relato é de um momento em que Nick entra em seu quarto e diz para ela confiar nele e seguir os homens que estão no corredor: “- Está tudo bem. É Mayday. Vá com eles.” (ATWOOD, 2017, p.346). É o uso da palavra Mayday (código para reconhecer quem faz parte da oposição) que determina a ida de June. É apenas uma palavra que determina sua decisão. June entra na camionete dos homens que a esperam e seu diário acaba. Duzentos anos depois, seus escritos são revisitados e estudados por pesquisadores e historiadores a fim de entender a configuração social de Gilead. Esse olhar para o passado com o intuito de compreender o futuro é possível pelo presente; esse tempo crônico de 
que fala Benveniste (1989) é significado somente através do presente da enunciação.

\section{Considerações}

Buscou-se discutir neste trabalho como as mulheres eram vistas e tratadas pela reformulação do Estado em O Conto da Aia, utilizando, para tanto, a teoria da enunciação de Émile Benveniste, relida por Dufour, apontando como a tríade eu-tu-ele/ela aparecem na narrativa, a partir da análise das falas da personagem principal, June. O foco da análise se deu a partir da condição de não-pessoa, o ele/ela, na construção da narrativa das mulheres de Gilead. No entanto, foi preciso, para se chegar à análise da não-pessoa, percorrer, também, pelas raras, mas não menos importantes, passagens em que June se vê colocada na posição de tu e, consequentemente, colocada na posição de $e u$ do discurso.

No decorrer da análise, foi possível verificar como as mulheres de Gilead são coisificadas por meio da impossibilidade de se colocarem como sujeitos participantes da sociedade e pelo cerceamento de suas vozes. Ao retirar o direito das mulheres de se imporem no discurso como eu, o sistema as condena à condição de objeto, roubando-lhes toda e qualquer oportunidade de existência como pessoa eu/tu. Para June, seu refúgio é recorrer a diálogos consigo mesma e utilizá-los para resistir a essa condição, desdobrando-se entre eu e tu em vários momentos explicitados na narrativa.

Com isso, constata-se, a partir da discussão acerca da forma linguística denominada por Benveniste como não-pessoa, o apagamento das mulheres como sujeitos do seu dizer. É o outro que é responsável por falar por elas, confirmando, mais uma vez, quem pode ou não dizer Ego na sociedade que se instaurou.

Analisando o contexto em que estava inserida a protagonista, foi possível averiguar as novas condições às quais as mulheres eram submetidas. Condições essas de não ser, não pertencer, não se colocar como sujeito, não ser autorizado a participar desse novo cenário instaurado pelo novo sistema. Consequentemente, 
mulheres foram reduzidas ao que Benveniste $(1976 ; 1989)$ vai chamar de nãopessoa e ao que Dufour (2000) vai chamar de ninguém, pois está ausente. 


\section{Referências}

ATWOOD, Margaret. O Conto da Aia. Tradução de Ana Deiró. Rio de Janeiro: Rocco, 2017.

BENVENISTE, Émile. Problemas de Linguística Geral I. 5. ed. Letras e Linguística. V. 8. São Paulo: Ed. da Universidade de São Paulo, 1976.

BENVENISTE, Émile. Problemas de Linguística Geral II. Campinas, São Paulo: Pontes, 1989.

BÍBLIA. Provérbios. In BÍBLIA. Português. Sagrada Bíblia Católica: Antigo e Novo Testamentos. Tradução de José Simão. São Paulo: Sociedade Bíblica de Aparecida, 2008.

CAVALHEIRO, Juciane dos Santos. A relação de alteridade entre as personagens de a metamorfose. DLCV - Língua, Linguística \& Literatura, v. 4, n. 1, p. 77-93, 2006.

DUFOUR, Dany-Robert. Os mistérios da trindade. Rio de Janeiro: Companhia de Freud, 2000.

FLORES, Valdir do Nascimento. Introdução à Teoria Enunciativa de Benveniste. 1. ed. São Paulo: Parábola, 2013.

KEHL, Maria Rita. A constituição literária do sujeito moderno. 2001. Disponível em: https://pt.scribd.com/doc/19133258/Maria-Rita-Kehl-Aconstituicao-literaria-do-sujeito-moderno. Acesso em: 13 jan. 2020.

NEUMANN, Daiane. A linguagem e a vida: reflexões acerca de língua e literatura. Desenredo (PPGL/UPF), v. 14, p. 435-443, 2018.

Artigo recebido em 20 de maio de 2020 e aceito em 28 de julho de 2020. 